\title{
The Prevalence of Syphilis Is Associated with the Prevalence of Male Point-Concurrency: An Ecological Analysis
}

\author{
Chris Richard Kenyon ${ }^{1,2 *}$, Kara Osbak ${ }^{3}$ \\ ${ }^{1}$ Sexually Transmitted Infections HIV/STI Unit, Institute of Tropical Medicine, Antwerp, Belgium \\ ${ }^{2}$ Division of Infectious Diseases and HIV Medicine, University of Cape Town, Cape Town, South Africa \\ ${ }^{3} \mathrm{HIV} / \mathrm{STI}$ Unit, Institute of Tropical Medicine, Antwerp, Belgium \\ Email: ckenyon@itg.be, kosbak@itg.be
}

Received 24 April 2015; accepted 21 June 2015; published 24 June 2015

Copyright (C) 2015 by authors and Scientific Research Publishing Inc.

This work is licensed under the Creative Commons Attribution International License (CC BY).

http://creativecommons.org/licenses/by/4.0/

(c) $\underset{\mathrm{EY}}{\mathrm{C}}$ Open Access

\section{Abstract}

Objective: The prevalence of syphilis differs considerably between different populations and individual level risk factors such as number of sex partners seem unable to completely explain these differences. The effect of network level factors, such as the prevalence of partner concurrency, on syphilis prevalence has not hitherto been investigated. Study design: Linear regression was performed to assess the relationship between the prevalence of male concurrency and prevalence of syphilis in each of 11 countries for which we could obtain comparable data. The data for concurrency prevalence was taken from the WHO/Global Programme on AIDS (GPA) sexual behavioural surveys. Syphilis prevalence rates were obtained from antenatal syphilis serology surveys done in the same countries. In addition, we used linear regression to assess if there was a relationship between syphilis and concurrency prevalence of various racial and ethnic groups within the United States and South Africa. Results: In the international study, we found a strong relationship between the prevalence of male concurrency and syphilis prevalence $(r=0.79, P=0.003)$. In the subnational studies, the relationship between concurrency and syphilis prevalence was positive in all cases but was only statistically significant so in the case of South Africa's racial groups $(r=0.98$, $P=0.01$ ). Conclusions: The findings of an ecological-level association between syphilis and partner concurrency need to be replicated but suggest that efforts directed towards decreasing partner concurrency may reduce syphilis prevalence.

\section{Keywords}

Concurrency, Sexual Network, HIV, Syphilis

\footnotetext{
${ }^{*}$ Corresponding author.
}

How to cite this paper: Kenyon, C.R. and Osbak, K. (2015) The Prevalence of Syphilis Is Associated with the Prevalence of Male Point-Concurrency: An Ecological Analysis. World Journal of AIDS, 5, 131-139. 


\section{Introduction}

Why do some ethnic groups have a prevalence of syphilis of up to five times greater than others within the same location and why does syphilis prevalence vary by an even greater degree between countries [1]-[4]? Syphilis is a sexually transmitted infection (STI) caused by infection with Treponema pallidum subspecies pallidum. STIs are transmitted over networks of sexual partnerships, and hence the structure of these networks will influence how quickly and extensively STIs will spread. The importance of these population-level characteristics was noted by Aral et al. "Whereas individual-level parameters may influence which individuals in a given population acquire infection, it is population-level parameters that affect the presence and prevalence of infection to be acquired" [5]. In keeping with this interpretation, whilst individual-level risk factors such as the numbers of lifetime sexual partners are associated with risk of syphilis at an individual level [6] [7], populations with higher syphilis prevalence rates do not have higher numbers of lifetime sexual partners [1] [7] [8]. This is true when comparing ethnic groups within a country and when comparing international variations [1] [9] [10]. Although countries in Southern and Eastern Africa have until recently had amongst the highest syphilis prevalence rates in the world, [2]-[4] the number of lifetime sexual partners in this region is the same or lower than low syphilis prevalence parts of the world such as Europe [8] [10]. Might network-level factors be responsible?

Although there is still debate on this topic [11] [12], a population/network-level determinant that has been shown to explain a large part of the variation in HIV and STI prevalence by ethnic group in the USA and Southern Africa is the variation in concurrency rates - that is the proportion of sexual partnerships that overlap in time as opposed to running sequentially [13]-[15]. Concurrency increases the transmission of STIs because concurrent partnerships link sex partners together into large connected components-if people have more than one partner at a point in time, then this interlinks them into a connected sexual network [16]. This effect has been shown at an individual level, where having more than one partner at a time increases the risk of transmitting syphilis [17]. The effect of concurrency on syphilis transmission may also be evident at a population level. This paper tests the hitherto untested theory that populations with a high prevalence of male-concurrency have a higher prevalence of syphilis.

\section{Methodology}

\subsection{International Comparisons}

\subsubsection{Point-Concurrency}

To overcome the problems of comparability with different datasets using different methodologies and definitions of concurrency, we used one of the only multinational surveys that assesses concurrency using the same methodology. These are the WHO/Global Programme on AIDS (GPA) sexual behavioural surveys conducted in 1989/1990. All 11 countries that performed these surveys between 1989 and 1990 and asked questions about concurrency are evaluated here [18] [19]. All these surveys followed WHO/GPA protocols. These included that national probability samples of the general populations aged 15 to 49 were utilized. In two cases, Manila and Rio de Janeiro, the samples were representative of these large cities rather than being nationally representative. All samples were selected based on the probability principle with various designs depending on national factors. A two stage sampling strategy was the norm, with census enumeration areas as the first stage and households as the second. The sample sizes were typically 1000 - 3000 men and women. Response rates were high in all cases. The variable for concurrency was derived from the question "Do you now have one or more than one spouse/ regular partner?” The concurrency variable we used in our analysis was the percentage of men 15 - 49 year old who had more than one sexual partnership active at the time of the survey. Only 7 of the countries surveyed asked the women if they had concurrent partners. As a result, we limited our analysis to male concurrency (defined below). We related point-concurrency prevalence to estimated syphilis prevalence.

\subsubsection{Syphilis Prevalence}

Syphilis prevalence rates were obtained from a search for representative antenatal survey-based samples from the same countries that the WHO/GPA surveys were conducted. The first suitable study conducted after the WHO/GPA survey (1989) was selected. The search was conducted in the PubMed/Medline and Web of Science databases in August 2013. Studies were included if they were representative antenatal-based samples and the diagnosis of syphilis was based on at least a non-treponemal test. In a number of studies the diagnosis of syphilis was confirmed with a treponeme-specific test (see Table 1 for details). In the case of Singapore, it was not 
Table 1. International comparison of syphilis prevalence with male point-concurrency.

\begin{tabular}{|c|c|c|c|c|c|}
\hline & $\begin{array}{l}\text { Concurrency } \\
\text { prevalence } \\
(\%)\end{array}$ & $\begin{array}{c}\text { Multiple } \\
\text { partners }^{\mathrm{a}} \\
\text { (Men/Women) }\end{array}$ & $\begin{array}{l}\text { Syphilis } \\
\text { Prevalence } \\
\text { (\%) }\end{array}$ & Syphilis survey details & $\begin{array}{l}\text { Antenatal } \\
\text { attendees } \\
\text { tested for } \\
\text { syphilis at } \\
\text { first visit } \\
\quad(\%)\end{array}$ \\
\hline $\begin{array}{l}\text { Central } \\
\text { African } \\
\text { Republic }\end{array}$ & 20 & $2 / 1$ & 6.7 & $\begin{array}{c}\text { All } 481 \text { pregnant women attending one of three antenatal clinics in } \\
\text { Bangui for first antenatal visit between January and March } 1986 . \\
\text { Tested with VDRL and confirmed with TPHA. [36] }\end{array}$ & 56.0 \\
\hline Brazil & 7 & $10 / 1$ & 1.6 & $\begin{array}{l}\text { All } 1515 \text { pregnant women attending antenatal clinics at Hospital } \\
\text { Regional Norte do Paraná between June } 1996 \text { and June } 1998 \text { were } \\
\text { tested for syphilis using VDRL and confirmed with FTA. [37] }\end{array}$ & 53.0 \\
\hline Côte d'Ivoire & 36 & $9 / 1$ & 3.8 & $\begin{array}{l}\text { A systematic review and meta-analysis of STI prevalence among } \\
\text { pregnant women attending antenatal care facilities in } \\
\text { sub-Saharan Africa was used to provide an estimate of syphilis } \\
\text { prevalence for the years } 1990-1990 \text { in West Africa. } 17 \text { studies } \\
\text { from } 6 \text { countries provided the estimate. [38] }\end{array}$ & 92.1 \\
\hline Kenya & 13 & $4 / 1$ & 7.2 & $\begin{array}{l}\text { All } 10267 \text { pregnant women attending } 10 \text { selected antenatal clinics } \\
\text { in Nairobi in 1994. Tested via RPR only. No confirmatory testing. } \\
\text { [39] }\end{array}$ & 58.8 \\
\hline Lesotho & 55 & $7 / 0$ & 11.3 & $\begin{array}{c}\text { A random sample of } 27715 \text { - } 49 \text { year olds living in } 29 \text { villages in } \\
\text { rural Lesotho in 1995. Tested with RPR and confirmed with } \\
\text { TPHA. [40] }\end{array}$ & 66.9 \\
\hline Philippines & 3 & $7 / 1$ & 0.2 & Antenatal survey in 2009. [30] & - \\
\hline Singapore & 2 & $3 / 0$ & 1.05 & $\begin{array}{l}\text { All 14,841 pregnant women attending the antenatal clinic, } \\
\text { University Hospital, Kuala Lumpur in 1989. Tested with VDRL } \\
\text { and conformed with TPHA. [41] }\end{array}$ & 94.1 \\
\hline Sri Lanka & 2 & $0 / 0$ & 1.0 & Antenatal survey in 1990. [42] & 45.9 \\
\hline Thailand & 3 & $11 / 0$ & 0.1 & $\begin{array}{l}1021 \text { consecutive pregnant women registering for their first visit } \\
\text { to two antenatal clinics in two hospitals } \\
\text { (in Bangkok and Chiang Rai) in 1996. Tested with VDRL } \\
\text { (Chiang Rai) or RPR (Bangkok) and confirmed with TPHA. [43] }\end{array}$ & - \\
\hline Zambia & 22 & $7 / 1$ & 8.5 & $\begin{array}{l}\text { All } 9145 \text { pregnant women from } 22 \text { antenatal clinics in all } \\
\text { provinces, including rural and urban areas were tested for syphilis } \\
\text { in 1994. Testing was via RPR and confirmation by TPHA. [44] }\end{array}$ & 43.3 \\
\hline Tanzania & 18 & $5 / 3$ & 7.3 & $\begin{array}{l}\text { All } 17813 \text { women from } 57 \text { clinics in ten geographical regions } \\
\text { attending antenatal clinics for the first time for any pregnancy } \\
\text { were tested for syphilis between October } 2003 \text { and January } 2004 \text {. } \\
\text { RPR testing only, no confirmatory TPHA. [45] }\end{array}$ & 36.9 \\
\hline
\end{tabular}

Abbreviations: FTA—Fluorescent treponemal antibody-absorption test, RPR—Rapid Plasma Reagin, TPHA—Treponema pallidum Hemagglutination Assay, VDRL-Venereal Diseases Research Laboratory. ${ }^{\text {a}}$ The GPA did not assess lifetime sex partners but did assess multiple partners in the previous year. This was defined as the percentage of men/women who reported five or more non-regular partners in the last 12 months.

possible to find a suitable estimate of syphilis prevalence and the prevalence estimate of the neighboring country of Malaysia was used. To assess the impact of inclusion of Singapore in the analysis, we repeated the linear regression analyses with and without Singapore.

\subsubsection{Percentage of Antenatal Clinic Attendees Tested for Syphilis}

We used the percentage of antenatal clinic attendees who were tested for syphilis at their first antenatal visit as a proxy for the strength of the national syphilis control programme. We obtained this data from the World Health Organization's Global Health Observatory Data Repository, and used the data from the year as soon after 1989 as possible [16].

\subsubsection{Intranational Comparisons}

We compared the association between syphilis and concurrency prevalence by ethnic group in two countries 
with available data.

\subsubsection{United States (USA)}

The USA sexual behaviour data was taken from the 1992 National Health and Social Life Survey (NHSLS). This was a cross-sectional study that used a nationally representative stratified random sample of 3432 women and men between the ages of 18 and 59 [20]. The syphilis prevalence data (cases/100,000 population) is based on diagnoses of primary and secondary syphilis for the year 1992 and was taken from a Centers for Disease Control and Prevention report [21]. This data is based on STI surveillance systems operated by state and local STI control programs.

\subsection{South Africa}

\subsubsection{Inter (Black) Ethnic Group Comparison}

The Carletonville Youth Survey consisted of a random sample of 723 men and 784 women between the ages of 14 - 24 living in a township outside of Carletonville-a gold mining town in South Africa. Households were selected via a two-stage random sampling technique. The sampling scheme was arranged so as to be self-weighting. Respondents were questioned about sexual partnerships and tested for syphilis via a Fluorescent treponemal antibody absorption test. For a more detailed description of the survey methodology see Auvert et al. [22]. A previous study demonstrated a high degree of homophilous partnering by ethnicity in the participants of the Carletonville Youth Survey [23]. Thus differences between ethnic groups in the patterns of sexual mixing may play a role in sustaining differences in STIs between these ethnic groups [24].

\subsubsection{Inter Racial Comparison}

Since 1990, South Africa has conducted annual nationally-representative antenatal syphilis and HIV surveys. In only one of these, the 1991 report, was the prevalence of syphilis reported by racial group. We used this report to provide syphilis prevalence estimates by race in South Africa. In this survey a total of 17,318 antenatal women were tested for syphilis via the Rapid Plasma Reagin or the Venereal Diseases Research Laboratory test [25].

Sexual behavior data was obtained from the 2003 South African Demographic Health Survey (DHS). This was a 2-stage sample which was designed to be representative for the 9 provinces, urban versus rural areas and the four major racial groups in the country. The survey was conducted on 7966 women and 3930 men. All were 15 - 49 year old [26].

\subsection{Statistical Analyses}

We related the prevalence of syphilis to the point prevalence of concurrency through linear regression, whereby the Pearson product moment correlation coefficient $r$ reflects the association between variables. All analyses were conducted with Stata 13.0 (College Station, TX). In all cases concurrency was defined as the proportion of persons who reported having two or more partners either on the day of the interview (point-prevalence) or over the previous year (cumulative prevalence). In the case of the South African datasets the syphilis prevalence is reported for the whole population (men and women) combined. In the case of the antenatal sample, this is because no men were included and in the case of the Carletonville Survey, the sizes of the ethnic groups were too small when split into men and women. In the South African analyses the syphilis prevalence was related to the prevalence of concurrency and number of lifetime partners in men. In the USA analyses the prevalence of syphilis was related to the prevalence of concurrency and lifetime number of partners in the opposite sex. The reasons for relating syphilis prevalence to concurrency prevalence in the opposite sex are that concurrency serves to increase the risk of transmission of an STI to one's sex partner but does not increase the risk of STI acquisition to the index respondent (over the risk imposed by having an additional partner) [1] [15]. A number of studies have validated the utility of this approach in ecological studies that assess the effect of concurrency on STI transmission [27]-[29].

Where the data was available we also related the prevalence of syphilis to the lifetime numbers of sex partners. This data was available in the sexual behavioural datasets from the Carletonville Youth Survey. In the international comparative study we used the percentage of men and women who had more than five sex partners in the past year. In the South African race group analysis we used the percentage of men who reported two or more partners in the past year. A P-value of $<0.05$ was considered statistically significant. 


\section{Results}

\subsection{International Comparisons}

In the international comparative study, we found evidence of a relationship between the prevalence of male concurrency and syphilis prevalence $(r=0.79, P=0.003$; see Table 1 and Figure 1$)$. There was no correlation between syphilis prevalence and the percentage of antenatal clinic attendees who were tested for syphilis at their first visit $(r=-0.28, P=0.47)$. There was also no correlation between the percentage of men/women who reported five or more non-regular partners in the last 12 months and syphilis prevalence (Men: $\mathrm{r}=-0.11, \mathrm{P}=0.74$; Women: $r=0.29, \mathrm{P}=0.38$ ).

\subsection{Sub-National Comparisons}

There was evidence of a statistically significant relationship between the prevalence of syphilis and male concurrency in South Africa's racial groups $(r=0.98, P=0.01$; see Table 2) and a borderline significant relationship in South Africa's black ethnic groups $(r=0.77, P=0.07)$. In the USA the relationship between concurrency and syphilis was positive but did not reach statistical significance.

Table 2. Subnational comparisons of syphilis prevalence/incidence with point-concurrency and lifetime number of reported sex partners (Data sources described in methods section).

\begin{tabular}{|c|c|c|c|c|}
\hline & $\mathbf{n}$ & Life time sex partners ${ }^{a}$ & Concurrency prevalence $^{\mathrm{a}}$ & Syphilis prevalence/incidence ${ }^{b}$ \\
\hline \multicolumn{5}{|c|}{ South Africa-black ethnic groups } \\
\hline Sotho & 209 & 5.3 & 13.7 & 8.6 \\
\hline Zulu & 89 & 4.1 & 27.1 & 11.2 \\
\hline Xhosa & 357 & 4.1 & 22.6 & 11.7 \\
\hline Tswana & 458 & 5.3 & 18.4 & 9.8 \\
\hline Tsonga & 28 & 4.3 & 22 & 14.3 \\
\hline \multirow[t]{2}{*}{ Other } & 40 & 4.6 & 28.9 & 17.5 \\
\hline & & $\mathrm{r}=-0.44, \mathrm{P}=0.37$ & $\mathrm{r}=0.77, \mathrm{P}=0.07$ & \\
\hline \multicolumn{5}{|c|}{ South Africa-racial groups } \\
\hline Coloured & 348 & 8.2 & 6.5 & 6.3 \\
\hline Black & 2237 & 16.0 & 9.2 & 8.3 \\
\hline White & 156 & 4.9 & 2.0 & 0.4 \\
\hline \multirow[t]{2}{*}{ Asian } & 282 & 9.4 & 1.4 & 1.2 \\
\hline & & $\mathrm{r}=0.77, \mathrm{P}=0.22$ & $\mathrm{r}=0.98, \mathrm{P}=0.01$ & \\
\hline \multicolumn{5}{|l|}{ USA } \\
\hline \multicolumn{5}{|l|}{ Men } \\
\hline Non Hispanic White & 866 & & 3.1 & 1.8 \\
\hline Non Hispanic Black & 164 & & 11.3 & 106.7 \\
\hline \multirow[t]{2}{*}{ Hispanic } & 109 & & 8.9 & 10.3 \\
\hline & & & $r=0.26, P=0.83$ & \\
\hline \multicolumn{5}{|l|}{ Women } \\
\hline Non Hispanic White & 1003 & & 1.3 & 1.3 \\
\hline Non Hispanic Black & 259 & & 3.7 & 87.8 \\
\hline \multirow[t]{2}{*}{ Hispanic } & 161 & & 4.9 & 7 \\
\hline & & & $\mathrm{r}=0.76, \mathrm{P}=0.45$ & \\
\hline
\end{tabular}

${ }^{\mathrm{a}}$ In the case of the South African results, the values for the sexual behavior variables are those of the men only. ${ }^{\mathrm{b}}$ Syphilis prevalence figures are reported for the South African studies and incidence figures for the USA. In the case of the USA incidence figures refer to cases of primary and secondary syphilis per 100,000 persons per year. The South African syphilis prevalence figures for the racial groups are from the antenatal survey (women only) and those for the ethnic groups are from the Carletonville Youth Survey and for men and women combined. 


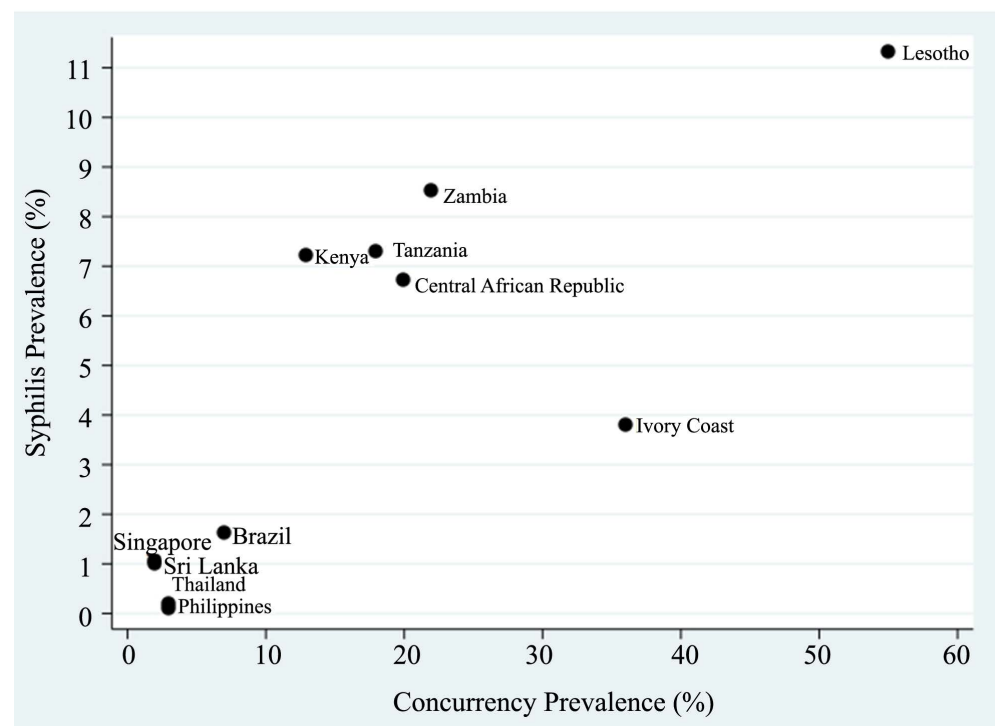

Figure 1. Association between syphilis prevalence and point-prevalence of male Concurrency-derived from GPA Behavioral Surveys 1989-1990 (r = $0.79 ; \mathrm{P}=0.003)$.

There was no statistically significant relationship between total number of sex partners and syphilis incidence/ prevalence.

\section{Discussion}

There are a number of limitations with our analysis. We were unable to find an antenatal or population based estimate of syphilis for Singapore and we thus used that of the neighboring Malaysia. We do not, however, believe that this estimate is too inaccurate as the prevalence of syphilis invirtually the entire western Pacific region is low [2] [10] [30] and the prevalence of syphilis in high-risk groups in Singapore is low [31] [32]. The prevalence of syphilis in sex workers (3\% in 1988) and men who have sex with men (5.5\% in 2012] in Singapore is considerably lower than the corresponding figures for high syphilis prevalence regions [31] [32]. In addition, when we repeated the analysis without Singapore it had little effect on the results. A further problem is that some of the syphilis prevalence estimates are based on antenatal surveys which may not be representative of the prevalence of syphilis in the general population.

As far as our subnational comparisons are concerned the results should be viewed with caution due to a number of reasons. Only in the case of the Carletonville Survey were we able to obtain the syphilis and sexual behavior variables from the same survey. Using data from different surveys is problematic for a number of reasons. These include that the surveys were carried out at different times and they may have classified ethnicity in slightly different ways.

It should be noted that the epidemiology of syphilis is complex and numerous factors that were not investigated here, such as the prevalence of condom usage and the efficacy of STI treatment could influence the prevalence of syphilis. Whilst it is likely that differential access to STI treatment explains a part of the differences in syphilis prevalence internationally, it is unlikely to be the major factor [10] [33] [34]. Thus there was no evidence, that we could find, that STI treatment capability is poorer in high syphilis prevalence countries than other low and middle income countries [34]. There was also no correlation between syphilis testing at antenatal visits and national syphilis prevalence rates. In addition, differential access to therapy is thought unlikely to explain more than a part of the ethnic discrepancy in syphilis prevalence in the USA [6].

\section{Conclusion}

Our study supports the findings of others which find that differences in individual-level risk factors such as number of sexual partners, are unable to explain more than a part of the differences in syphilis rates between 
different ethnic groups [1] [35]. This study suggests that network-level factors, such as the proportion of partnerships that run concurrently, may explain a large part of the variationsin syphilis incidence/prevalence [1] [9] [35]. This is the first study to test if the prevalence of concurrency and syphilis are correlated. Its finding of a positive relationship needs to be confirmed in other datasets. The fact that syphilis is a risk factor for a range of adverse outcomes including HIV infection makes this an important topic for further research.

\section{Acknowledgements}

We thank Bertran Auvert, Catherine Campbell and Brian Williams who designed the Carletonville Youth Survey for giving us access to this dataset.

\section{Competing Interests}

The authors declare they have no competing interests.

\section{References}

[1] Morris, M., Kurth, A.E., Hamilton, D.T., Moody, J. and Wakefield, S. (2009) Concurrent Partnerships and HIV Prevalence Disparities by Race: Linking Science and Public Health Practice. American Journal of Public Health, 99, 10231031.

[2] World Health Organization (2011) Prevalence and Incidence of Selected Sexually Transmitted Infections, Chlamydia trachomatis, Neisseria gonorrhoeae, Syphilis and Trichomonas vaginalis. World Health Organization, Geneva.

[3] World Health Organization (1995) Global Prevalence and Incidence of Selected Curable Sexually Transmitted Diseases: Overview and Estimates. World Health Organization, Geneva.

[4] World Health Organization (2001) Global Prevalence and Incidence of Selected Curable Sexually Transmitted Diseases: Overview and Estimates. World Health Organization, Geneva.

[5] Aral, S.O., Lipshutz, J. and Blanchard, J. (2007) Drivers of STD/HIV Epidemiology and the Timing and Targets of STD/HIV Prevention. Sexually Transmitted Infections, 83, i1-i4. http://dx.doi.org/10.1136/sti.2007.027169

[6] Hahn, R.A., Magder, L., Aral, S., Johnson, R.E. and Larsen, S.A. (1989) Race and the Prevalence of Syphilis Seroreactivity in the United States Population: A National Sero-Epidemiologic Study. American Journal of Public Health, 79, 467-470. http://dx.doi.org/10.2105/AJPH.79.4.467

[7] Buve, A., Weiss, H.A., Laga, M., Van Dyck, E., Musonda, R., Zekeng, L., et al. (2001) The Epidemiology of Gonorrhoea, Chlamydial Infection and Syphilis in Four African Cities. AIDS, 15, S79-S88. http://dx.doi.org/10.1097/00002030-200108004-00009

[8] Wellings, K., Collumbien, M., Slaymaker, E., Singh, S., Hodges, Z., Patel, D., et al. (2006) Sexual Behaviour in Context: A Global Perspective. Lancet, 368, 1706-1728. http://dx.doi.org/10.1016/S0140-6736(06)69479-8

[9] Kenyon, C., Dlamini, S., Boulle, A., White, R.G. and Badri, M. (2009) A Network-Level Explanation for the Differences in HIV Prevalence in South Africa's Racial Groups. African Journal of AIDS Research, 8, 243-254. http://dx.doi.org/10.2989/AJAR.2009.8.3.1.922

[10] Kenyon, C., Colebunders, R. and Buyze, J. (2014) Classification of Incidence and Prevalence of Certain Sexually Transmitted Infections by World Regions. International Journal of Infectious Diseases, 18, 73-80. http://dx.doi.org/10.1016/j.ijid.2013.09.014

[11] Sawers, L. and Stillwaggon, E. (2010) Concurrent Sexual Partnerships Do Not Explain the HIV Epidemics in Africa: A Systematic Review of the Evidence. Journal of the International AIDS Society, 13, 34. http://dx.doi.org/10.1186/1758-2652-13-34

[12] Epstein, H. and Morris, M. (2011) Concurrent Partnerships and HIV: An Inconvenient Truth. Journal of the International AIDS Society, 14, 13. http://dx.doi.org/10.1186/1758-2652-14-13

[13] Morris, M. (2010) Barking up the Wrong Evidence Tree. Comment on Lurie \& Rosenthal, “Concurrent Partnerships as a Driver of the HIV Epidemic in Sub-Saharan Africa? The Evidence Is Limited”. AIDS and Behavior, 14, 31-33; Discussion 34-37. http://dx.doi.org/10.1007/s10461-009-9639-6

[14] Johnson, D.R., Bradshaw, D., Pillay-Van, W.V. and Rehle, T. (2009) Sexual Behaviour Patterns in South Africa and Their Association with the Spread of HIV: Insights from a Mathematical Model. Demographic Research, 21, 289-340. http://dx.doi.org/10.4054/DemRes.2009.21.11

[15] Morris, M., Epstein, H. and Wawer, M. (2010) Timing Is Everything: International Variations in Historical Sexual Partnership Concurrency and HIV Prevalence. PLoS ONE, 5, e14092. 
http://dx.doi.org/10.1371/journal.pone.0014092

[16] Morris, M. and Kretzschmar, M. (1997) Concurrent Partnerships and the Spread of HIV. AIDS, 11, 641-648. http://dx.doi.org/10.1097/00002030-199705000-00012

[17] Koumans, E.H., Farley, T.A., Gibson, J.J., Langley, C., Ross, M.W., McFarlane, M., et al. (2001) Characteristics of Persons with Syphilis in Areas of Persisting Syphilis in the United States: Sustained Transmission Associated with Concurrent Partnerships. Sexually Transmitted Diseases, 28, 497-503. http://dx.doi.org/10.1097/00007435-200109000-00004

[18] Ferry, B., Deheneffe, J., Mamdani, M. and Ingham, R. (1995) Characteristics of Surveys and Data Quality. In: Cleland, J.G., Ferry, B., Eds., Sexual Behaviour and AIDS in the Developing World, Taylor \& Francis, London.

[19] Carael, M. (1995) Sexual Behaviour. In: Cleland, J.G. and Ferry, B., Eds., Sexual Behaviour and AIDS in the Developing World, Taylor \& Francis, London.

[20] Laumann, E.O. (1994) The Social Organization of Sexuality: Sexual Practices in the United States. University of Chicago Press, Chicago.

[21] US Department of Health and Human Services (1996) Sexually Transmitted Disease Surveillance, 1995. Centers for Disease Control and Prevention, Atlanta.

[22] Auvert, B., Ballard, R., Campbell, C., Carael, M., Carton, M., Fehler, G., et al. (2001) HIV Infection among Youth in a South African Mining Town Is Associated with Herpes Simplex Virus-2 Seropositivity and Sexual Behaviour. AIDS, 15, 885-898. http://dx.doi.org/10.1097/00002030-200105040-00009

[23] Kenyon, C. and Colebunders, R. (2013) Birds of a Feather: Homophily and Sexual Network Structure in Sub-Saharan Africa. International Journal of STD \& AIDS, 24, 211-215. http://dx.doi.org/10.1177/0956462412472455

[24] Kenyon, C., Colebunders, R., Buve, A. and Hens, N. (2013) Partner-Concurrency Associated with Herpes Simplex Virus 2 Infection in Young South Africans. International Journal of STD \& AIDS, 24, 804-812. http://dx.doi.org/10.1177/0956462413482810

[25] Department of Health (1992) Syphilis Screening in Women Attending Antenatal Clinics. Epidemiological Comments, 19, 166-171.

[26] Department of Health, Medical Research Council, OrcMacro (2007) South African Demographic and Health Survey 2003. Department of Health, Pretoria.

[27] Kenyon, C. and Colebunders, R. (2012) Strong Association between Point-Concurrency and National Peak HIV Prevalence. International Journal of Infectious Diseases, 16, e826-e827. http://dx.doi.org/10.1016/j.ijid.2012.05.008

[28] Kenyon, C., Colebunders, R. and Hens, N. (2013) Determinants of Generalized Herpes Simplex Virus-2 Epidemics: The Role of Sexual Partner Concurrency. International Journal of STD \& AIDS, 24, 375-382. http://dx.doi.org/10.1177/0956462412472816

[29] Kenyon, C.R. and Colebunders, R. (2014) Strong Association between the Prevalence of Bacterial Vaginosis and Male Point-Concurrency. European Journal of Obstetrics. Gynecology and Reproductive Biology, 172, 93-96.

[30] World Health Organization (2009) Indicator and Measurement Registry Version 1.6.0. Syphilis Seropositivity among Antenatal Care Attendees. http://apps.who.int/gho/indicatorregistry/App Main/view indicator.aspx?iid=3249

[31] Chua, A.C., Chen, M.I.C., Cavailler, P., Jiang, L.L., Abdullah, M.R., Ng, O.T., et al. (2013) Challenges of Respondent Driven Sampling to Assess Sexual Behaviour and Estimate the Prevalence of Human Immunodeficiency Virus (HIV) and Syphilis in Men Who Have Sex with Men (MSM) in Singapore. Annals Academy of Medicine Singapore, 42, 350353.

[32] Lim, K.B., Srivasin, V., Gan, S.L., Thirumoorthy, T., Nadarajah, M., Sng, E.H., et al. (1989) Chlamydial Infection in Female Prostitutes in Singapore. Singapore Medical Journal, 30, 263-264.

[33] Aral, S.O., Over, M., Manhart, L. and Holmes, K.K. (2006) Sexually Transmitted Infections. In: Jamison, D.T. and Mosley, W.H., Eds., Disease Control Priorities in Developing Countries: Health Policy Responses to Epidemiological Change, World Bank, Washington DC, 653-689.

[34] Johnson, L.F., Dorrington, R.E., Bradshaw, D. and Coetzee, D.J. (2011) The Effect of Syndromic Management Interventions on the Prevalence of Sexually Transmitted Infections in South Africa. Sexual \& Reproductive Healthcare, 2, 13-20. http://dx.doi.org/10.1016/j.srhc.2010.08.006

[35] Laumann, E.O. and Youm, Y. (1999) Racial/Ethnic Group Differences in the Prevalence of Sexually Transmitted Diseases in the United States: A Network Explanation. Sexually Transmitted Diseases, 26, 250-261. http://dx.doi.org/10.1097/00007435-199905000-00003

[36] Blankhart, D., Muller, O., Gresenguet, G. and Weis, P. (1999) Sexually Transmitted Infections in Young Pregnant Women in Bangui, Central African Republic. International Journal of STD \& AIDS, 10, 609-614. http://dx.doi.org/10.1258/0956462991914753 
[37] Reiche, E.M., Morimoto, H.K., Farias, G.N., Hisatsugu, K.R., Geller, L., Gomes, A.C., et al. (2000) Prevalence of American Trypanosomiasis, Syphilis, Toxoplasmosis, Rubella, Hepatitis B, Hepatitis C, Human Immunodeficiency Virus Infection, Assayed through Serological Tests among Pregnant Patients, from 1996 to 1998, at the Regional University Hospital Norte do Parana. Revista da Sociedade Brasileira de Medicina Tropical, 33, 519-527. http://dx.doi.org/10.1590/S0037-86822000000600002

[38] Chico, R.M., Mayaud, P., Ariti, C., Mabey, D., Ronsmans, C. and Chandramohan, D. (2012) Prevalence of Malaria and Sexually Transmitted and Reproductive Tract Infections in Pregnancy in Sub-Saharan Africa: A Systematic Review. Journal of the American Medical Association, 307, 2079-2086. http://dx.doi.org/10.1001/jama.2012.3428

[39] Temmerman, M., Fonck, K., Bashir, F., Inion, I., Ndinya-Achola, J.O., Bwayo, J., et al. (1999) Declining Syphilis Prevalence in Pregnant Women in Nairobi since 1995: Another Success Story in the STD Field? International Journal of STD and AIDS, 10, 405-408. http://dx.doi.org/10.1258/0956462991914339

[40] Colvin, M. and Sharp, B. (2000) Sexually Transmitted Infections and HIV in a Rural Community in the Lesotho Highlands. Sexually Transmitted Infections, 76, 39-42. http://dx.doi.org/10.1136/sti.76.1.39

[41] Goh, T.H. and Ngeow, Y.F. (1989) Serological Screening for Syphilis during Pregnancy in a Multiethnic Asian Population. Asia-Oceania Journal of Obstetrics and Gynaecology, 15, 67-70. http://dx.doi.org/10.1111/j.1447-0756.1989.tb00154.x

[42] Abeyewickreme, I. (1990) An Evaluation of Some Aspects of the Screening Programmes for Syphilis and Gonorrhoea in Sri Lanka. Post Graduate Institute of Medicine, Colombo.

[43] Kilmarx, P.H., Black, C.M., Limpakarnjanarat, K., Shaffer, N., Yanpaisarn, S., Chaisilwattana, P., et al. (1998) Rapid Assessment of Sexually Transmitted Diseases in a Sentinel Population in Thailand: Prevalence of Chlamydial Infection, Gonorrhoea, and Syphilis among Pregnant Women-1996. Sexually Transmitted Infections, 74, 189-193. http://dx.doi.org/10.1136/sti.74.3.189

[44] Makasa, M., Fylkesnes, K., Michelo, C., Kayeyi, N., Chirwa, B. and Sandoy, I. (2012) Declining Syphilis Trends in Concurrence with HIV Declines among Pregnant Women in Zambia: Observations over 14 Years of National Surveillance. Sexually Transmitted Diseases, 39, 173-181. http://dx.doi.org/10.1097/OLQ.0b013e31823b23a4

[45] Swai, R.O., Somi, G.R., Matee, M.I.N., Killewo, J., Lyamuya, E.F., Kwesigabo, G., et al. (2006) Surveillance of HIV and Syphilis Infections among Antenatal Clinic Attendees in Tanzania-2003/2004. BMC Public Health, 6, 91. 